\title{
Quadricuspid mitral valve: Of clefts, scallops, and indentations
}

Giovanni Benfari, MD, Lucia Rossetti, MD, Andrea Rossi, MD, and Giovanni Battista Luciani, MD,

Verona, Italy

From the Divisions of Cardiology and Cardiac Surgery, University of Verona, Verona, Italy.

Disclosures: Authors have nothing to disclose with regard to commercial support.

Received for publication March 18, 2016; revisions received April 8, 2016; accepted for publication April 18, 2016; available ahead of print May 19, 2016.

Address for reprints: Giovanni Battista Luciani, MD, Division of Cardiac Surgery, Department of Surgery,

University of Verona, O.C.M. Piazzale Stefani 1, Verona, 37126 Italy (E-mail: giovanni.luciani@univr.it).

J Thorac Cardiovasc Surg 2016;152:e51-3

$0022-5223 / \$ 36.00$

Copyright $(5) 2016$ by The American Association for Thoracic Surgery

http://dx.doi.org/10.1016/j.jtcvs.2016.04.066

\begin{tabular}{|c|c|}
\hline $\begin{array}{l}\text { TCS } \\
\text { VIDEO } \\
\text { CLIII } \\
\text {.1.m. }\end{array}$ & Video clip is available online. \\
\hline
\end{tabular}

Isolated mitral valve cleft is an uncommon cause of congenital mitral regurgitation typically affecting the aortic or

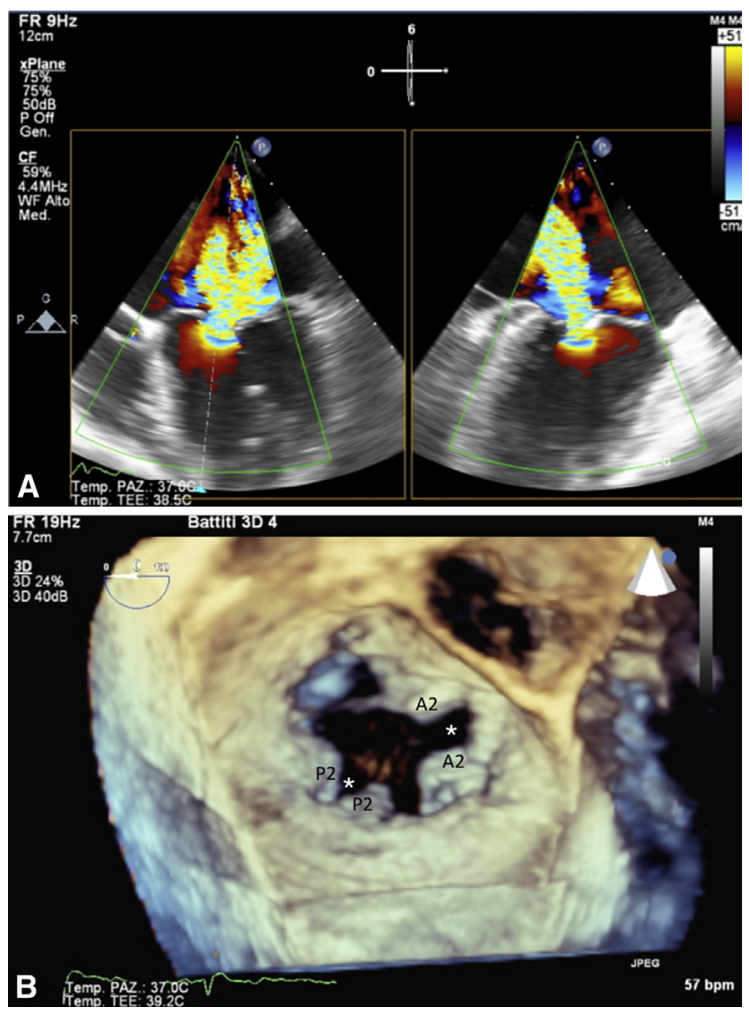

FIGURE 1. X-plane 2-dimensional color Doppler images showing severe mitral regurgitation with mildly eccentric holosystolic jet (A) and atrial 3-dimensional zoom view of the mitral valve (B). A large cleft within the aortic (anterior) scallop A2 is shown to reach the mitral annulus just below the mitroaortic junction. A second cleft within the mural (posterior) scallop P2, reaching the posterior mitral annulus, is also detectable (X7-2t transesophageal probe, optimized on 4 heart beats). Asterisk indicates mitral valve cleft.

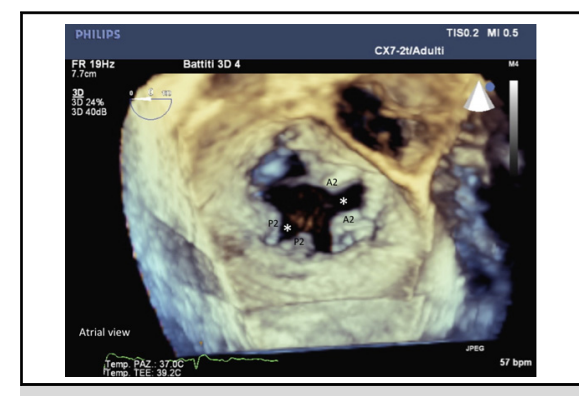

Atrial view 3D image of severe mitral regurgitation caused by double mitral valve cleft.

\section{Central Message}

This is an uncommon case of "true" cleft in both the mural and the aortic mitral valve leaflets. The lesions reached the mitral annulus, giving rise to a 4-leaflet mitral valve.

See Editorial Commentary page e53.

anterior leaflet. More rarely, an isolated cleft of the mural or posterior leaflet has been observed. The presence of cleft in both the aortic and mural mitral valve leaflets represents an exceptional feature, with only 3 previous reports to date. ${ }^{1-3}$ Detailed review of previous reports, however, has often evidenced eccentric location and incomplete segmentation (ie, not reaching the annulus) of the so-called clefts. ${ }^{1-3}$ This observation suggests that these may perhaps represent deeper indentations between well-defined scallops of

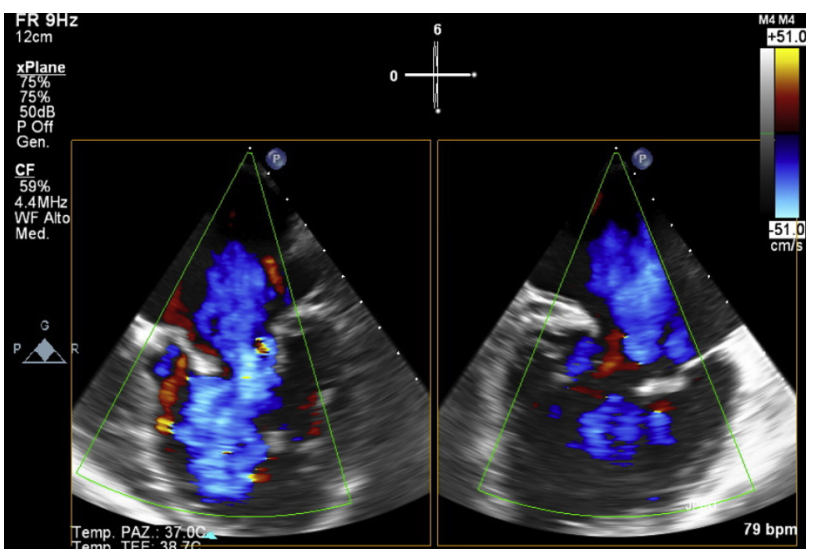

VIDEO 1. Color Doppler 2-dimensional record showing severe mitral regurgitation with mildly eccentric holosystolic jet (X7-2t transesophageal probe, X-plane mode). 


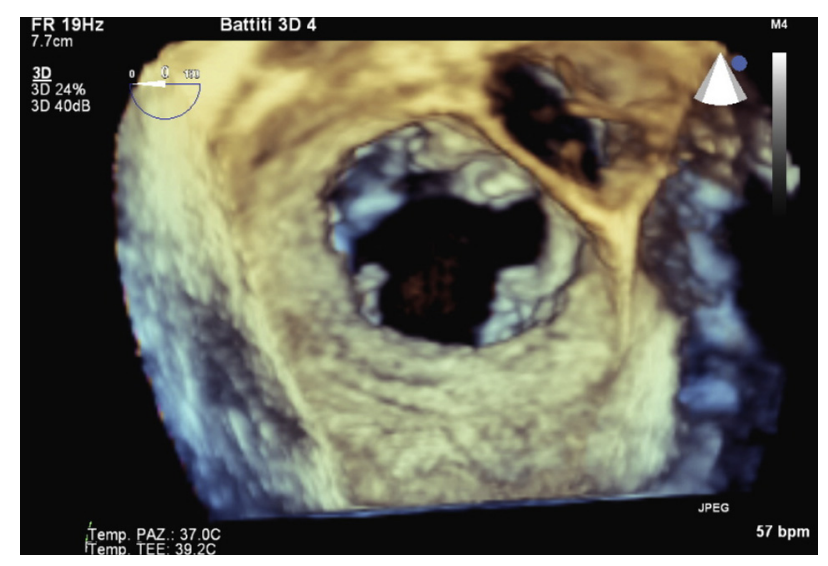

VIDEO 2. Atrial view of the mitral valve. A large cleft within the aortic scallop A2 is shown to reach the mitral annulus just below the mitroaortic junction. A second cleft within the mural scallop P2, reaching the posterior mitral annulus, is also detectable (X7-2t transesophageal probe, 3-dimensional zoom optimized on 4 heart beats).

otherwise anatomically normal mitral valves, rather than true congenital anomalies of the mitral valve.

To the best of our knowledge, ours is the first case of "true" cleft in both the aortic and mural mitral valve leaflets. To distinguish it from previous reports, here clefts are defined as lesions reaching the anterior and posterior mitral annulus (atrioventricular junction). The 2 main leaflets of the mitral valve (aortic and mural) were thus divided into nearly 4 symmetric segments, giving rise to a 4-leaflet mitral valve. The defect was initially suspected on the basis of transthoracic echocardiography, and then a diagnosis was made on the basis of 3-dimensional transesophageal echocardiography, on which severe mitral regurgitation was evident (Figure 1 and Video 1), and

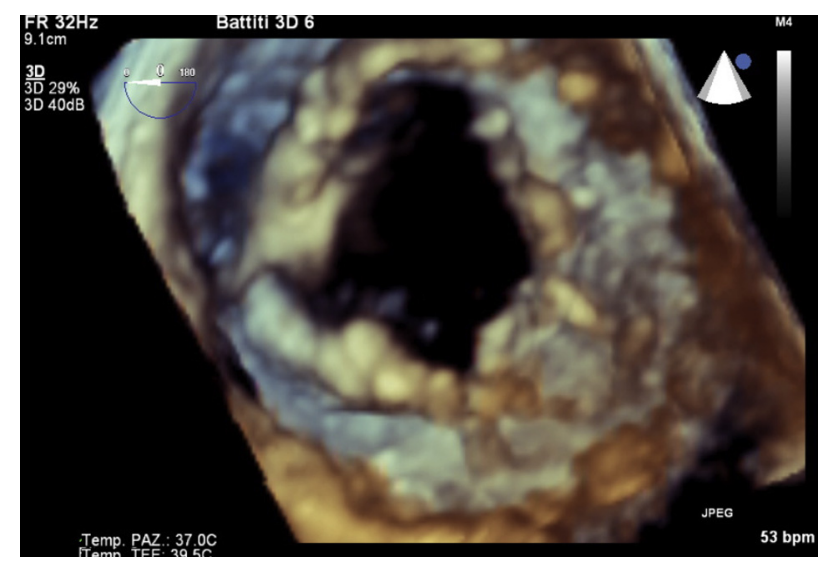

VIDEO 3. Ventricular view of the mitral valve. A large cleft between within the aortic scallop A2 is shown. A second smaller cleft within the mural scallop P2 is also detectable (X7-2t transesophageal probe, 3-dimensional zoom optimized on 4 heart beats and cropped offline with QLAB version 9).
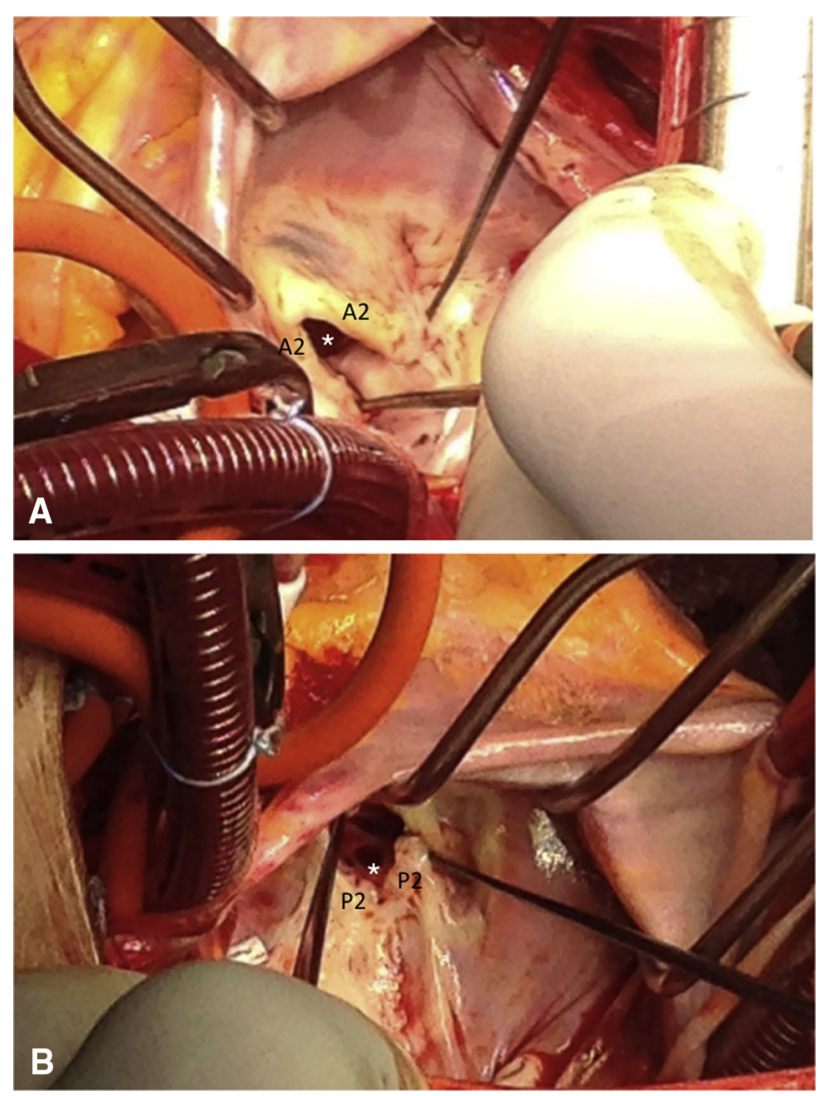

FIGURE 2. Operative view of the aortic (A) and mural (B) mitral leaflets after left atrial incision. Two hooks lifting the cranial and caudal segments of the scallops A2 and P2 are visible, where a deep cleft reaching respectively the anterior and the posterior mitral annuli is visible. Asterisk indicates the position of the anterior cleft (A) and the posterior cleft (B).

the structural details of the defect were characterized by 3-dimensional reconstruction (Figure 1 and Videos 2 and 3). Intraoperative findings confirmed the transesophageal echocardiographic images, disclosing a typical, large cleft in the aortic mitral leaflet (A2) and a specular lesion affecting the mural mitral leaflet (P2; Figure 2). The lesion was repaired by apposition of both the anterior and the posterior mitral clefts with direct suture and by posterior ring annuloplasty with bovine pericardium. Postoperative transesophageal echocardiography showed thickened mitral valve leaflets with only trivial residual mitral regurgitation and a mildly accelerated left ventricular filling (mean gradient of $5 \mathrm{~mm} \mathrm{Hg}$ ), which was confirmed by predischarge transthoracic echocardiography.

Preoperative distinction of multiple and deeper indentations in anatomically normal or mixomatous mitral valves from isolated clefts of the aortic, mural, or both mitral leaflets is often difficult, ultimately relying on surgical confirmation. We propose here a differentiation between true isolated mitral clefts versus more pronounced indentations between normal scallops on the basis of the symmetry of the defect and the ability to reach the mitral annulus. 
Whereas the former should be ascribed to congenital malformations of the mitral valve, the latter may represent anatomic variants of otherwise normal mitral leaflets or, more rarely, adaptive mechanisms of the mitral valve configuration, as observed in some disease conditions. ${ }^{4}$ In our case, real-time 3-dimensional echocardiography was highly predictive of detailed surgical anatomy and thus promises to be an invaluable tool in distinguishing between rare mitral valve malformations and variants of normal anatomy.

\section{References}

1. McDonald RW, Ott GY, Pantely GA. Cleft in the anterior and posterior leaflet of the mitral valve: a rare anomaly. J Am Soc Echocardiogr. 1994;7:422-4.

2. Mohammadi S, Bergeron S, Voisine P, Desaulniers D. Mitral valve cleft in both anterior and posterior leaflet: an extremely rare anomaly. Ann Thorac Surg. 2006;82:2287-9.

3. Müller H, Kalangos A, Fassa AA, Lerch R. Isolated cleft mitral valve with posterior and anterior clefts: a rare cause of congenital valve regurgitation. Echocardiography. 2010;27:E50-2.

4. Jouni H, Driver SL, Enriquez-Sarano M, Michelena HI. Cleft posterior mitra leaflet resembling a tri-leaflet mitral valve: a novel phenotypic association with hypertrophic cardiomyopathy. Eur Heart J. 2014;35:1623.

\title{
EDITORIAL COMMENTARY
}

\section{How many leaflets in the mitral valve?}

\author{
Robert H. Anderson, BSc, MD, FRCPath
}

From the Institute of Genetic Medicine, Newcastle University, Newcastle upon Tyne, United Kingdom.

Disclosures: Author has nothing to disclose with regard to commercial support.

Received for publication April 19, 2016; accepted for publication April 19, 2016; available ahead of print May 12, 2016.

Address for reprints: Robert H. Anderson, BSc, MD, FRCPath, 60 Earlsfield Rd, London SW18 3DN, United

Kingdom (E-mail: sejjran@ucl.ac.uk).

J Thorac Cardiovasc Surg 2016;152:e53-4

$0022-5223 / \$ 36.00$

Copyright (C) 2016 by The American Association for Thoracic Surgery

http://dx.doi.org/10.1016/j.jtcvs.2016.04.056

In their brief report published in this issue of The Journal, Benfari and colleagues ${ }^{1}$ demonstrate the presence of clefts within both the aortic and mural leaflets of the mitral valve, producing the arrangement they describe as being "quadricuspid." In making this designation, Benfari and

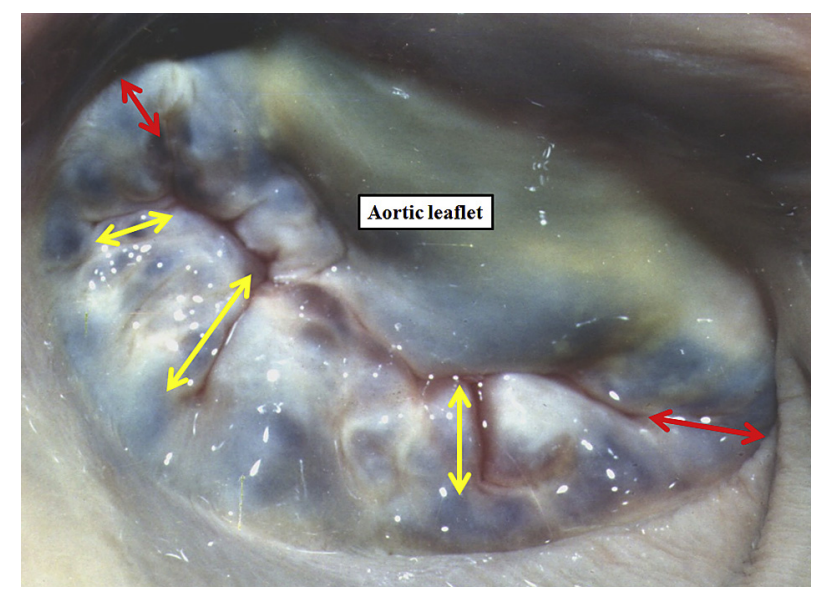

FIGURE 1. The solitary zone of apposition of the mitral valve, with slits in the mural leaflet.

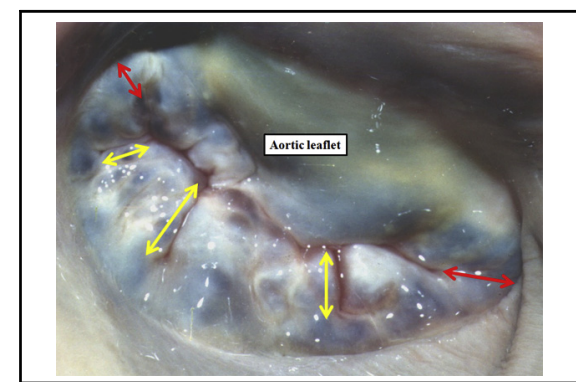

The solitary zone of apposition of the mitral valve, with slits in the mural leaflet.

\section{Central Message}

For the best description of the leaflets of the normal mitral valve and their component parts, we should take note of their pattern of closure.

See Article page e51.

colleagues $^{1}$ have shown their preference to retain the concept of the normal mitral valve possessing but 2 leaflets. Citing historical preference and mindful of their Italian heritage, they are happy to describe the 2 leaflets, as did Andreas Vesalius when working in Padova many centuries ago, as being aortic and mural. The obliquity of the left atrioventricular junction means that these designations are more accurate than the alternative and popular titles of anterior and posterior leaflets. Any anatomic structure with 2 moving components, of course, must then close along a solitary zone of apposition, as with the lips or the eyelids. Anatomists call this zone of apposition the "commissure." 